Jorge Camilo Mora, MD, MPH Associate Professor, Associate Dean for

Faculty Affairs, Director of Geriatric Medicine, Department of Translational Medicine, Herbert Wertheim FIU College of Medicine, Miami, FL

\section{Amalia Galindez, MD, FACP}

Clerkship Director and Chief, Division of Internal

Medicine; Interim Chair, Department of Translational

Medicine, Herbert Wertheim FIU College of Medicine,

Miami, FL

\title{
A large, painless bulla on the right foot
}
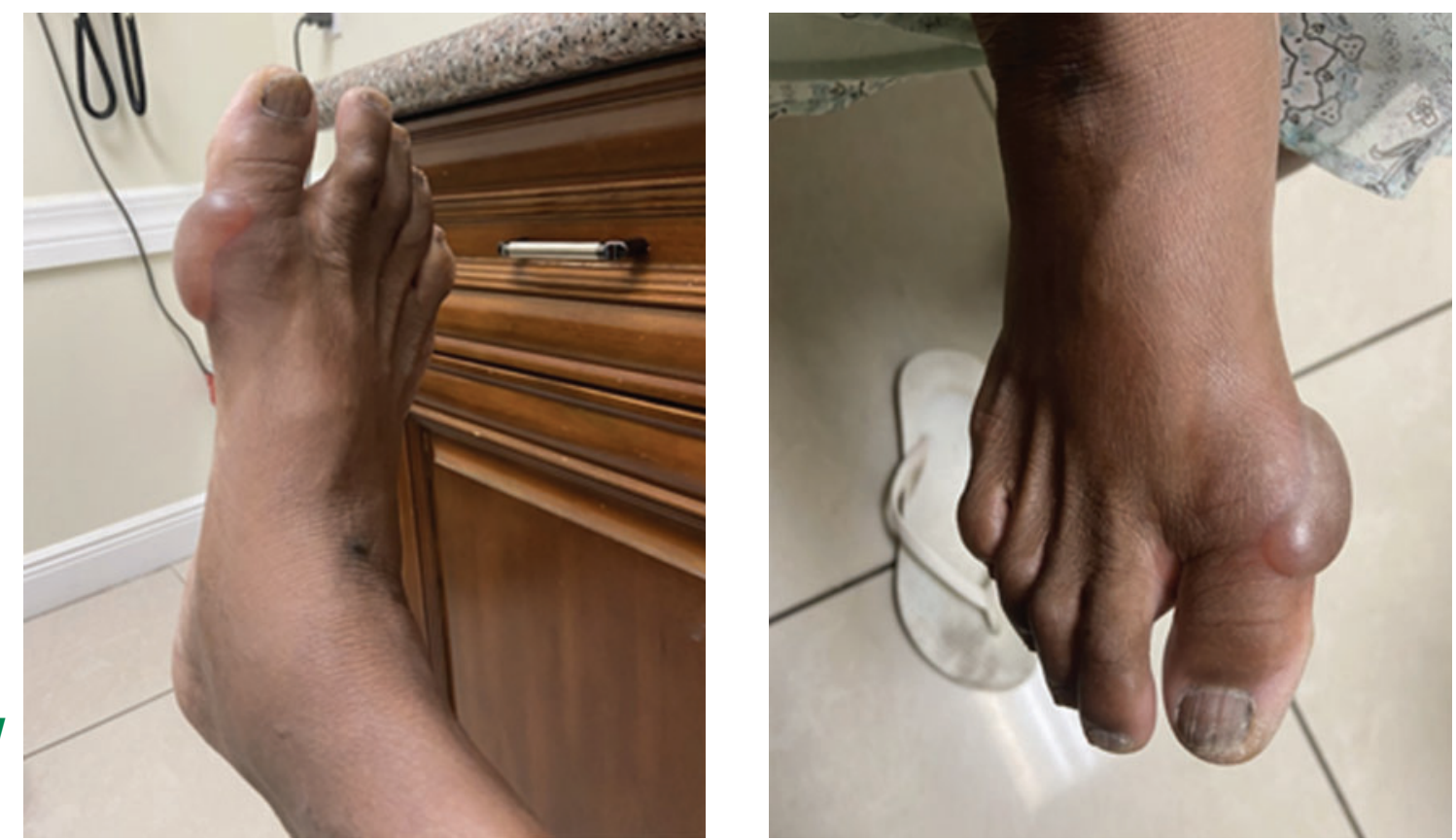

Figure 1. A large, tense, noninflammatory bulla $3.75 \mathrm{~cm}$ in diameter at the base of the first metatarsal joint of the right foot. The bulla contained clear fluid.

affects patients with prediabetes and diabetes

\section{A} 71-YEAR-OLD WOMAN WITH a history of diabetic neuropathy presented with a large, painless bulla on her right foot. She said it had started as a small vesicle but had slowly enlarged over the past 3 days. She had been working in her yard for several days prior to the development of the vesicle but did not sustain any insect bites or local trauma. She reported no fever or chills, and she had no history of skin vesicles or bullae or similar lesions on other parts of her body. No new medications had been recently prescribed.

Her medications at the time of presentation included metformin extended-release 500 doi:10.3949/ccjm.89a.21051 mg once daily, insulin lispro protamine-insulin lispro (75/25) 35 units twice daily, anastrozole $1 \mathrm{mg}$ daily, and gabapentin $600 \mathrm{mg}$ twice daily. She was not employed, mostly stayed at home, and had no history of smoking or alcohol or drug use. Comorbidities included breast cancer treated with chemotherapy and radiotherapy 1 year previously, type 2 diabetes mellitus with peripheral neuropathy, and hyperlipidemia.

On physical examination, the patient's vital signs were normal, and examination of the extremities revealed a large, tense, noninflammatory bulla at the base of the first metatarsal joint of the right foot, $3.75 \mathrm{~cm}$ in diameter and containing clear fluid (Figure 1). There were 
no other lesions on the extremities or trunk and no signs of local inflammation or spontaneous drainage. She had decreased perception to monofilament on both feet with normal peripheral pulses. As the bulla contained clear fluid, it was presumed to be sterile and thus, to avoid the risk of secondary infection, aspiration was not attempted. At a 4-week followup visit, the lesion had completely resolved, and the patient did not report any recurrence (Figure 2).

Laboratory testing during the follow-up visit revealed a hemoglobin A1c of $10.3 \%$ (reference range $<5.7 \%$ ), serum creatinine $0.87 \mathrm{mg} / \mathrm{dL}$ (reference range $0.60-0.93 \mathrm{mg} /$ $\mathrm{dL})$, and albumin-to-creatinine ratio $12 \mu \mathrm{g} /$ mg creatinine (reference range $<30 \mu \mathrm{g} /$ creatinine). Results of other laboratory testing were normal, including complete blood cell count, alanine transaminase, aspartate transaminase, total protein, and albumin.

\section{BULLOUS DISEASE OF DIABETES}

Bullosis diabeticorum is a noninflammatory blistering condition that affects patients with prediabetes and diabetes. ${ }^{1}$ The condition was first reported by Kramer in 1930, and the name was coined by Cantwell and Martz in $1967 .^{2}$ The blisters are tense with serous content. They are recurrent and spontaneous around acral regions, particularly on the lower extremities, including the toes and plantar area of the feet. They can also be present on the hands and forearms. They seldom present on the trunk. ${ }^{3-7}$ Vesicles and bullae can range in size from $0.5 \mathrm{~cm}$ to several centimeters. It is a rare disease, affecting approximately $0.5 \%$ of diabetic patients. Men are twice as likely as women to develop the condition.

Because bullosis diabeticorum mostly affects patients with diabetes mellitus who have associated nephropathy and neuropathy, it has been postulated that microangiopathy and disturbances in carbohydrate metabolism may lead to premature aging of connective tissue and other structural alterations in connective tissue ${ }^{8}$ increasing the risk of spontaneous appearance of these lesions. ${ }^{2}$ The lesions are usually self-limited and heal within 4 to 6 weeks without scarring. ${ }^{5}$

Treatment is conservative, and the blister

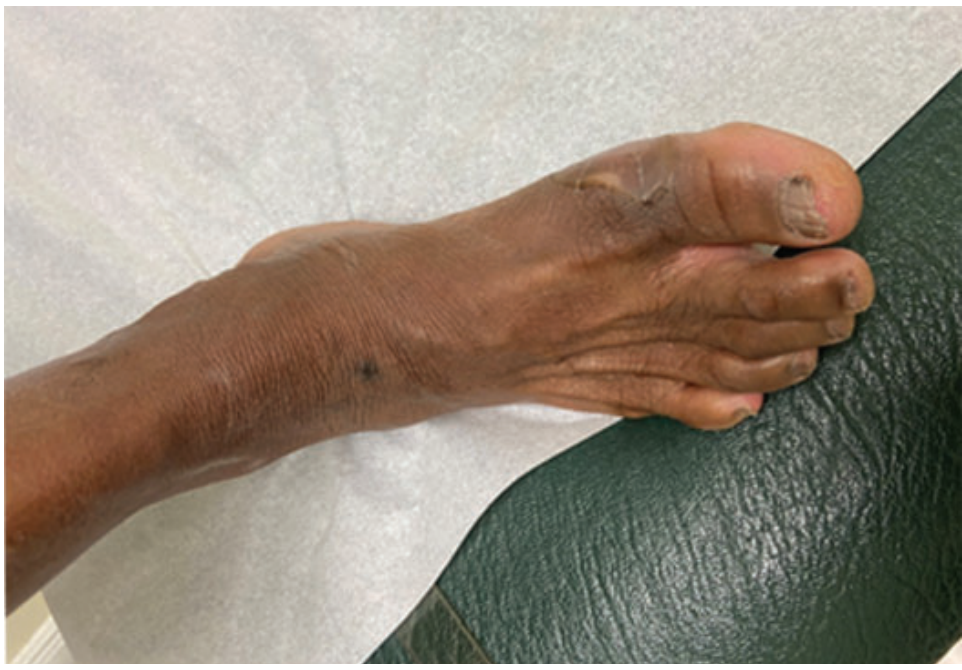

Figure 2. At a 4-week follow-up visit, the lesion had completely resolved with no signs of recurrence.

should be kept clean and protected to avoid secondary infection. No antibiotic therapy is required, although fluid aspiration and culture with use of oral antibiotics may be considered if secondary bacterial infection is suspected. ${ }^{6}$ Signs of possible infection include erythema, warmth, edema with surrounding inflammation, the presence of purulent fluid or drainage, and fever. The etiology is unclear.

The differential diagnosis for bullosis diabeticorum includes insect bite reaction, contact dermatitis with bullae, poison ivy dermatitis, bullous drug eruption, bullous impetigo, edema bullae, burns, and friction blister. ${ }^{7} \mathrm{Un}$ like friction blisters, bullosis diabeticorum often develops overnight and in the absence of known trauma. ${ }^{2}$ Friction blisters are generally associated with high levels of exercise and activity and are often seen in active military personnel or athletes with no underlying health issues, whereas bullosis diabeticorum commonly presents in the absence of foot trauma or pressure in vulnerable populations. Although rare, recurrent episodes leading to severe infection and ulceration have been described, with some bullae recurring years after the initial appearance. ${ }^{9}$

\section{TAKE-HOME POINTS}

Bullosis diabeticorum may be the first clinical presentation of hyperglycemia. ${ }^{2}$ Bullosis diabeticorum in patients with diabetes often signals poor diabetes control or the existence of associ-

\section{Men are twice as likely as women to develop bullosis diabeticorum}


ated neuropathy or nephropathy. Patients with this condition should be routinely screened for diabetes and for microscopic proteinuria and assessed for findings of peripheral neuropathy. Supportive care of the lesions with monitoring for signs of secondary infection is advised.

\section{DISCLOSURES}

The authors report no relevant financial relationships which, in the context of their contributions, could be perceived as a potential conflict of interest.

\section{REFERENCES}

1. Lopez PR, Leicht S, Sigmon JR, Stigall L. Bullosis diabeticorum associated with a prediabetic state. South Med J 2009; 102(6):643-644. doi:10.1097/SMJ.0b013e3181a506d6

2. Chouk C, Litaiem N. Bullosis diabeticorum. In: StatPearls. Treasure Island, FL: StatPearls Publishing; 2021. https://www.ncbi.nlm.nih.gov/ books/NBK539872/. Accessed December 7, 2021.

3. Mota AN, Nery NS, Barcaui CB. Case for diagnosis: bullosis diabeticorum. An Bras Dermatol 2013; 88(4):652-654. doi:10.1590/abd1806-4841.20132114

4. Oursler JR, Goldblum OM. Blistering eruption in a diabetic. Bullosis diabeticorum. Arch Dermatol 1991; 127(2):247-248.

doi:10.1001/archderm.1991.01680020115017

5. Bernstein JE, Medenica M, Soltani K, Griem SF. Bullous eruption of diabetes mellitus. Arch Dermatol 1979; 115(3):324-325. pmid:373635

6. Lipsky BA, Baker PD, Ahroni JH. Diabetic bullae: 12 cases of a purportedly rare cutaneous disorder. Int J Dermatol 2000; 39(3): 196-200. doi:10.1046/j.1365-4362.2000.00947.x

7. Zampella J, Craft N, Fox L, Goldsmith L. Bullosis diabeticorum. In: Goldsmith LA, ed. VisualDx. Rochester, NY: VisualDx; 2010.

8. Braverman IM, Keh-Yen A. Ultrastructural abnormalities of the microvasculature and elastic fibers in the skin of juvenile diabetics. J Invest Dermatol 1984; 82(3):270-274. doi:10.1111/1523-1747.ep12260279

9. Bhutani R, Walton S. Diabetic bullae. Br J Diabetes Vasc Dis 2015; 15(1):8-10. http://dx.doi.org/10.15277/bjdvd.2015.004

Address: Jorge Camilo Mora, MD, MPH, Director of Geriatric Medicine, Department of Translational Medicine, Herbert Wertheim FIU College of Medicine, 11200 SW 8th Street, Miami, FL 33199; Jcmora@fiu.edu 